\title{
Dynamic Effects in the Response of Offshore Wind Turbines Supported by Jackets under Wave Loading
}

\author{
Kai Wei ${ }^{1,2, *}$, Andrew T. Myers ${ }^{1}$, Sanjay R. Arwade ${ }^{3}$ \\ 1. Northeastern University, Boston, Massachusetts 02115, USA \\ 2. Southwest Jiaotong University, Chengdu, Sichuan 610031, China \\ 3. University of Massachusetts Amherst, Amherst, Massachusetts 01003 USA
}

\begin{abstract}
This paper studies the effect of structural dynamics on the response of an offshore wind turbine (OWT) supported by a jacket and subjected to wave loads. The study includes a series of time-domain dynamic analyses based on loading from regular and irregular wave histories and three example OWT support structures. The OWT support structures are proportioned to collectively span a broad range of the first fundamental period of an OWT supported by a jacket. For each dynamic analysis, a representative static analysis is also considered, and a dynamic amplification factor (DAF) is calculated and discussed as a function of wave height, wave regularity, and structural period. The results demonstrate that dynamic effects may amplify the structural response significantly for loading caused by smaller waves, but the amplification is minimal for loading caused by large waves, which have longer periods and, for the jacket geometry considered here, cause large wave-in-deck forces. For the specific scenarios and models considered in this paper, the structural period is found to have a small influence on the DAF.
\end{abstract}

Keywords: offshore wind turbine; dynamic effects; dynamic amplification; wave loading; jacket

\footnotetext{
${ }^{*}$ Corresponding author.

Ph.D. Associate professor at Department of Bridge Engineering, School of Civil Engineering, Southwest Jiaotong University; former Post-doctoral research associate at Northeastern University.

Address: 507 Tunnel Research Building, Southwest Jiaotong University, No. 111, North 1st Section of Second Ring Road, Chengdu, Sichuan 610031, China.
}

Tel: (+86) 028-87600630. Email: kaiwei@ swjtu.edu.cn 


\section{Introduction}

Performance-based design considers the diverse needs and objectives of owners and users of infrastructure by explicitly assessing the performance of structural designs during both expected and extreme loadings, the latter of which are anticipated to damage the structure [1]. Performance-based design relies on the assessment of the vulnerability of structures and on the recurrence of hazards, resulting in estimations of the probability of damage for the structure during its lifetime [2-7]. Such information is essential to understanding and mitigating the risk of hazards, whether natural or otherwise. In the initial development of performance-based design, structural assessments were first based on nonlinear static analyses (i.e., static pushover analyses [8]) which aimed to 'equivalently' represent dynamic loading. Such static approaches have been used widely to, for example, estimate the structural capacity of buildings under earthquakes [9], offshore platforms under wave loads [10] and offshore wind turbine (OWT) support structures under wind and wave loads [11]. While static pushover analysis provides a reasonable and practical way to assess a comprehensive range of structural behavior by scaling a static force distribution that is representative of expected dynamic loading [8], the implications of this static approximation are not well understood for OWT structures and the intent of this study is to provide insight into the practice of approximating dynamic loading with static loading to see if equivalent static approaches can be used to reasonably assess the performance of OWTs supported by jackets.

The preference for static analysis is due, in part, to the computational burden and greater overall complexity of modeling the dynamic response of a structure subject to time-varying loading [12]. The growth of computer processing power, however, has enabled the efficient assessment of structural performance using dynamic, time-domain analysis. In earthquake engineering, which has led the evolution of performance-based design, Vamvatsikos and Cornell started the transition to dynamic analysis with the development of the now widely-used method termed incremental dynamic analysis (IDA) [13]. In wind engineering, the influence of dynamic effects on structural inelastic behavior have been considered by Tabbuso et al. who developed a method based on dynamic inelastic models of building frames subject to stochastic wind with long duration [14] and by Judd and Charney who have studied the inelastic behavior of buildings using an IDA-based approach [15]. In offshore oil/gas engineering, dynamic methods have been 
established to estimate the behavior of offshore jacket platforms against environmental wave loading. Golafshani et al. have introduced the idea of Dynamic Incremental Wave Analysis (DIWA), which estimates capacities for oil/gas jacket structures through nonlinear dynamic analysis [16]. In offshore wind engineering, Taflanidis et al. have developed a surrogate model based on elastic dynamic analyses of OWTs supported by tripods to predict structural response under extreme wave and wind loads [7].

Although dynamic analysis is becoming more commonplace, static analysis remains popular because of its simplicity. For offshore structures, the difference between dynamic and static analyses in the response of offshore structures is still a subject of active research. For example, Jensen [17] studied the dynamic amplification factor (DAF) of a jack-up platform subjected to non-Gaussian wave loads and a single degree of freedom structural model. Golafshani et al. [16] studied oil/gas jacket platforms under wave loads and found that, for two different example platforms, the difference between the maximum structural base shear of dynamic and static analyses was either negligible (less than $0.5 \%$ ) or approximately $14 \%$, with dynamic analysis providing a larger maximum response. Horn et al. [18] investigated the dynamic amplification of drag dominated structures and found that simplified analytical methods were not accurate for considering dynamic amplification in irregular seas. Kim et al. [19] considered both static pushover and dynamic approaches to assess the response of a $5 \mathrm{MW}$ offshore wind turbine supported by a monopile subjected to seismic loading considering nonlinear soil-pile interaction and found pushover analysis compared well with dynamic analysis results.

This paper presents the results of a numerical study consisting of a series of time-domain dynamic analyses intended to provide a better understanding of the dynamic effects on the elastic response of OWTs supported by jackets and loaded by waves. Although explicit consideration of the inelastic response of an OWT during the design process is essential to a performance-based design framework, the scope of this study is focused on the elastic response. Consideration of the inelastic response, including dynamic effects, is an important area for further study. Wind loads are not considered in this study, partially to focus the scope of the study and partially because wave loads are expected to drive the dynamic response of the structure considered here during extreme conditions when the rotor will be parked and feathered to minimize thrust [20]. Figure 1 shows a schematic of an OWT supported by a jacket subjected to irregular waves and identifies key terms in this paper. The magnitude of the dynamic effect is quantified through dynamic 
amplification curves, which provide a dynamic amplification factor (DAF; i.e., the ratio between the maximum response of a dynamic analysis and an equivalent static analysis) as a function of environmental conditions. These curves are provided separately for multiple modeling conditions, including regular and irregular wave loading and three example structures that have fundamental periods of $2.5 \mathrm{~s}, 3.2 \mathrm{~s}$, and $4.9 \mathrm{~s}$. The paper is organized as follows: first the analysis procedure and structural models are defined, then results from the numerical study are presented, and finally the results are summarized to better understand the extent of dynamic effects in the assessment of the performance of an OWT supported by a jacket and loaded by waves.

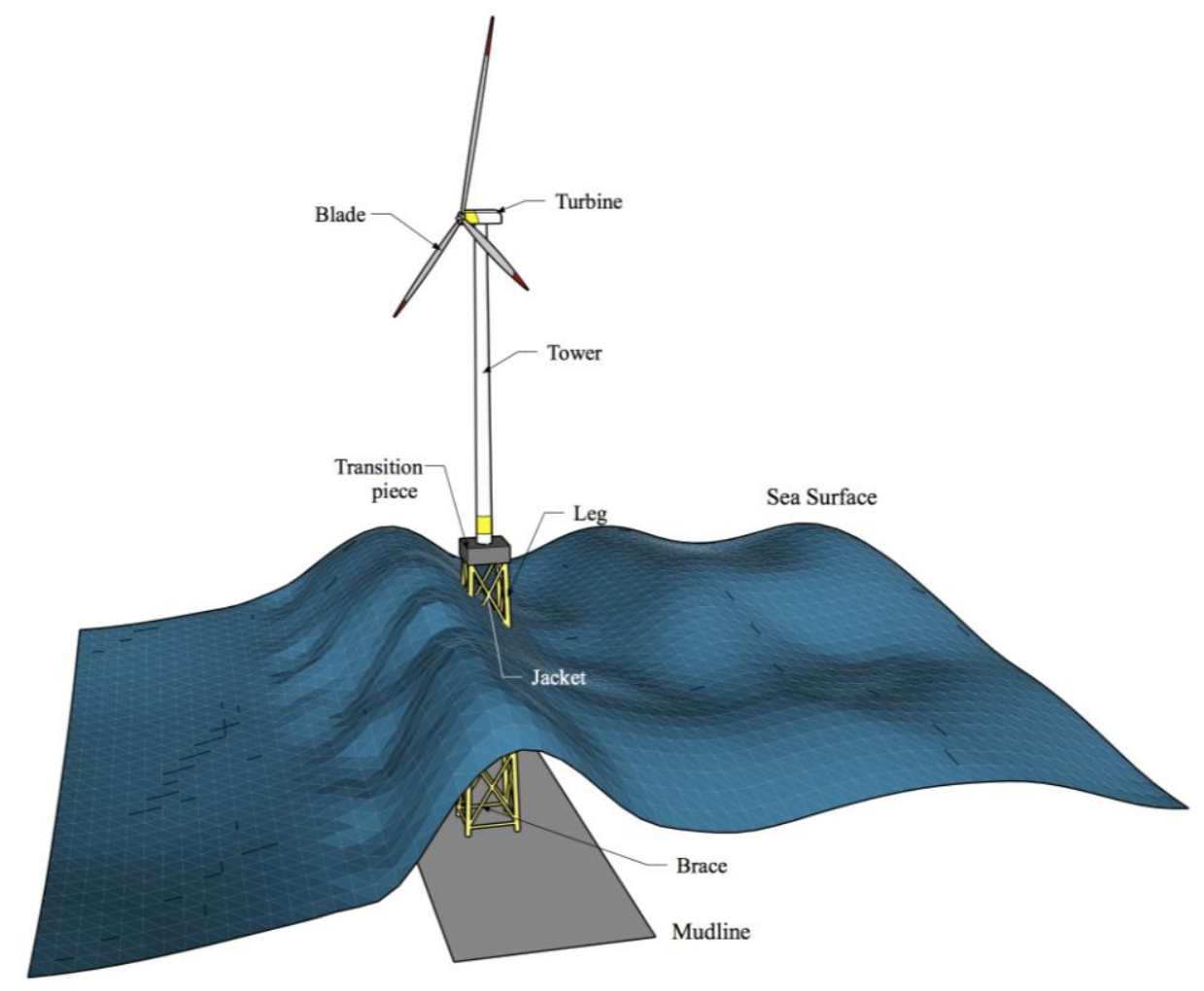

Figure 1 Illustration of an OWT supported by a jacket subject to loading from irregular waves.

\section{Model Definition and Analysis Procedure}

This section defines the structural model and analysis procedure used here to assess the extent of dynamic effects for three models of a jacket structure supporting an OWT and subjected to wave loading. The overall configuration of the considered jacket is based on the UpWind reference jacket [21], while the configuration of the OWT is based on the NREL offshore 5-MW baseline 
turbine [22]. Three different models of the jacket and OWT, each with different fundamental periods, are considered. The intent of studying these three models is to determine how dynamic amplification varies with the fundamental period of the structure and to give insight to practicing engineers applying the results in this paper to structural designs with different dynamic characteristics. As such, these three models are not intended to have a realistic geometry nor to have dynamic characteristics consistent with the NREL offshore 5-MW turbine. The three fundamental periods are selected to consider a range of periods and are realized by scaling the thickness of jacket and tower members in the model, thereby scaling the stiffness and mass of the model. Although wind loading during operational conditions is an important loading for the design of OWTs, Wei et al. [11] studied the ultimate capacity of non-operational OWTs under extreme wind and wave loadings and found that waves were the dominant source of extreme loads for the structural configuration considered here and for the following conditions: the rotor is oriented perpendicular to the wind, the blades are feathered to reduce aerodynamic forces, and the extreme waves contact the deck of the jacket, causing large wave-in-deck forces. Therefore, for this study, only the effect of wave loading is considered. All structural models are analyzed using the commercial finite element program USFOS [23].

\subsection{General structural configuration}

The tower and turbine in the three models considered here are based on the NREL offshore 5MW baseline wind turbine [22] supported by a jacket, installed in $50 \mathrm{~m}$ water depth. The jacket design is taken from the Upwind project [21] (Figure 2). The nacelle of the considered turbine has a mass of $240,000 \mathrm{~kg}$ and a diameter of $3.5 \mathrm{~m}$. The total mass of the rotor and blades is $107,000 \mathrm{~kg}$. The tower consists of pipe members with diameter and thickness varying along the height. The jacket consists of four legs with four levels of X-braces and cross braces. The four legs are oriented in plan to make a square section with edge length at the mudline of $12 \mathrm{~m}$ and at the deck of $8 \mathrm{~m}$. The bottoms of the legs are modeled as being fixed to the mudline. The connections between the braces and legs of the jacket are made with complete joint penetration welds between the contoured ends of the brace member and the continuous chord member (i.e., the leg) without stiffeners or grout. A concrete deck with a mass of $666,000 \mathrm{~kg}$ and dimensions of $4.0 \times 9.6 \times 9.6 \mathrm{~m}$ is positioned on top of the jacket and serves as a support platform for the tower 
of the turbine. The bottom of the concrete deck is $16 \mathrm{~m}$ above mean sea level and $66 \mathrm{~m}$ above the mudline.

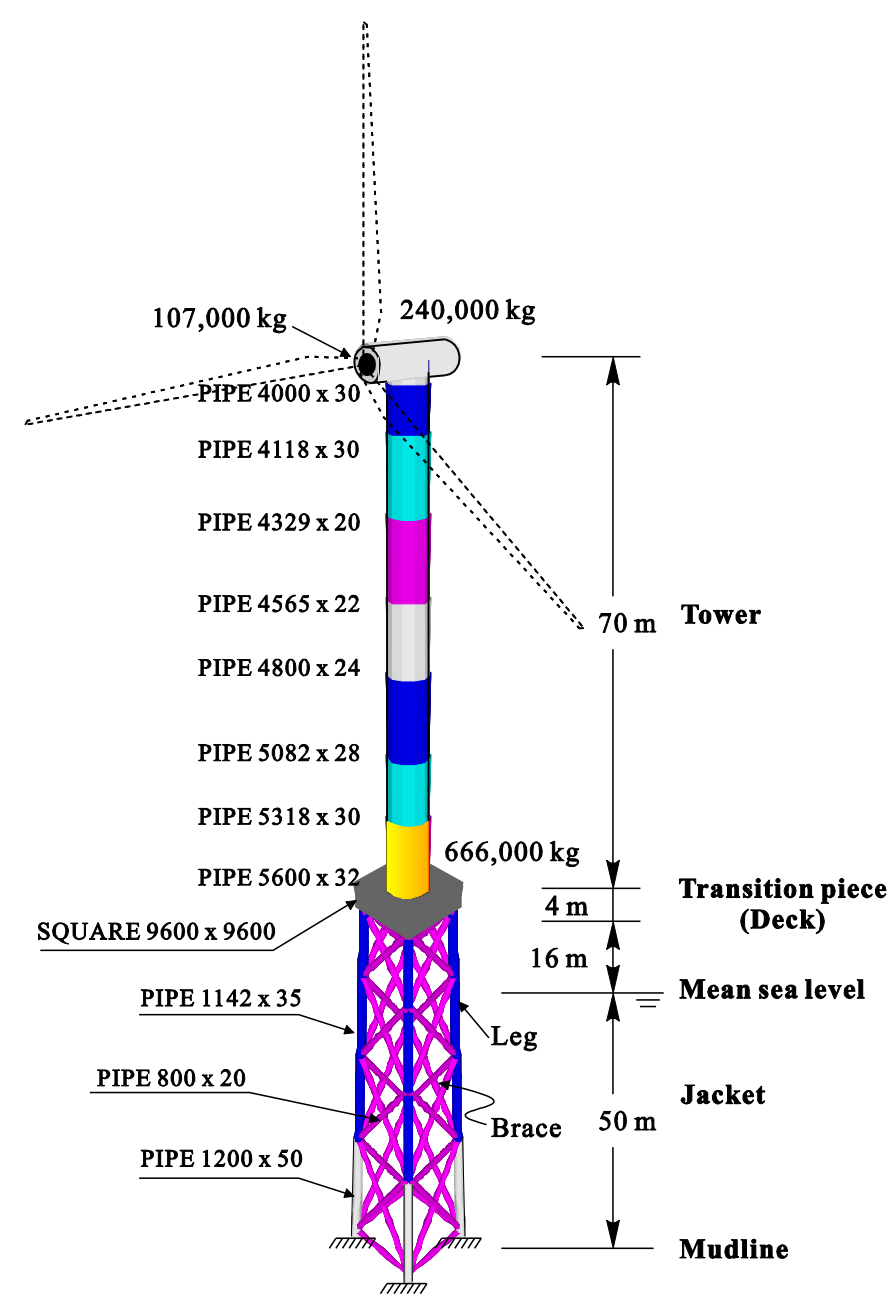

Figure 2 Schematic and dimensions of the NREL offshore 5-MW baseline turbine supported by the Upwind jacket. All dimensions are in millimeters unless otherwise specified.

The rotor and blades are modeled as a lumped mass of 107,000 $\mathrm{kg}$ horizontally offset from the center of the turbine by $3.5 \mathrm{~m}$. The tower is modeled with eight beam elements due to the nonuniform cross sections along the height. The transition piece is modeled using solid elements, which connect the bottom node of the tower to the top nodes of the four jacket legs, and the mass of the transition piece is distributed uniformly. The jacket is modeled with beam elements with an additional spring element included at the intersection between the central line of chord wall and the intersection between the chord wall and brace (Figure 3) to account for eccentric loading 
and flexibility of the joint itself. The axial, bending and torsional stiffness of the additional element are calculated within USFOS [23] based on the joint geometry.

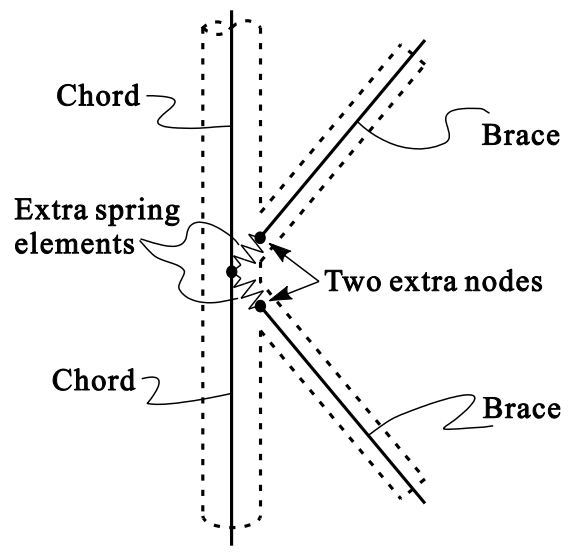

Figure 3 Modeling details of the chord to brace connection of the jacket in USFOS. Two extra spring elements are embedded between the brace and chord to account for eccentric loading and joint flexibility.

The tower and jacket are modeled as being made from a medium grade structural steel with Young's modulus of $210 \mathrm{GPa}$ and density of $8500 \mathrm{~kg} / \mathrm{m}^{3}$, which includes assumed masses accounting for paint, bolts, welds and all other additional masses that are not otherwise considered [11]. The jacket legs are assumed to be flooded and fully fixed at the mudline. Structural self-weight is included in the model as well as the buoyancy of the braces which are modeled as being non-flooded. Initial member imperfections are not considered in the model.

\subsection{Structural dynamic characteristics}

To study the relationship between the dynamic amplification and the fundamental period of the structure, three jacket models are considered. The first (Model \#1) is based directly on the properties described in the references [11, 21], which define the jacket, tower and turbine considered here. The other two models consider a stiffer model (Model \#2; the thicknesses of jacket legs, braces and tower members in Model \#1 are scaled by 2.0) and a more flexible model (Model \#3; the thicknesses of jacket legs, braces and tower members in Model \#1 are scaled by 0.40). The outer diameters for all the members are held constant for all three models to keep the hydrodynamic profile of the jacket consistent. The dimension and mass of the deck are not changed between the three models. The structural and material damping of all three models is modeled with Rayleigh damping, with $=2 \%[24,25]$ for periods of the $1^{\text {st }}$ and $5^{\text {th }}$ lateral 
vibration mode of the model [26]. It should be noted that there is no consensus in the literature for the structural periods used in calibrating Rayleigh damping parameters. The authors have simulated the structural response of Model \#3 using Rayleigh damping parameters calibrated to $1^{\text {st }}$ period combined with every other period between the $2^{\text {nd }}$ period $(1.3 \mathrm{~s})$ and the $30^{\text {th }}$ period $(0.1 \mathrm{~s})$ and found minimal difference in the results. This insensitivity to the calibration of the Rayleigh damping parameters over the considered range is logical because the OWT structure responds mostly in a cantilever mode, with minimal contributions from higher modes. Because of the symmetry of the structure considered here, mode shapes occur in pairs (fore-aft and sideside) and the fifth lateral mode therefore corresponds roughly to the third mode of the two dimensional cantilever. Therefore, by calibrating the Rayleigh damping to period of the $1^{\text {st }}$ and $5^{\text {th }}$ lateral vibration mode, the target damping magnitude is achieved approximately for the modes that contribute most to the structural response.

Table 1 provides the periods for the first five lateral vibration modes for each of the three models. The first five mode shapes and corresponding periods and frequencies for Model \#1 are plotted in Figure 4. These are consistent with the corresponding information in the reference report [21].

Table 1 The periods of the first five lateral vibration modes of three structural models considered here $(\mathrm{FA}=$ fore-aft direction; $\mathrm{SS}=$ side-to-side direction).

\begin{tabular}{|l|c|c|c|c|c|c|}
\hline & $\begin{array}{c}1 \text { st FA } \\
(\mathrm{s})\end{array}$ & $\begin{array}{c}\text { 1st SS } \\
(\mathrm{s})\end{array}$ & $\begin{array}{c}\text { 2nd FA } \\
(\mathrm{s})\end{array}$ & $\begin{array}{c}\text { 2nd SS } \\
(\mathrm{s})\end{array}$ & $\begin{array}{c}\text { 3rd FA } \\
(\mathrm{s})\end{array}$ & Description of the model \\
\hline Model \#1 & 3.23 & 3.23 & 0.87 & 0.87 & 0.29 & Reference design [21] \\
\hline Model \#2 & 2.46 & 2.46 & 0.71 & 0.70 & 0.25 & Reference thickness scaled by 2.0 \\
\hline Model \#3 & 4.90 & 4.90 & 1.25 & 1.25 & 0.38 & Reference thickness scaled by 0.4 \\
\hline
\end{tabular}




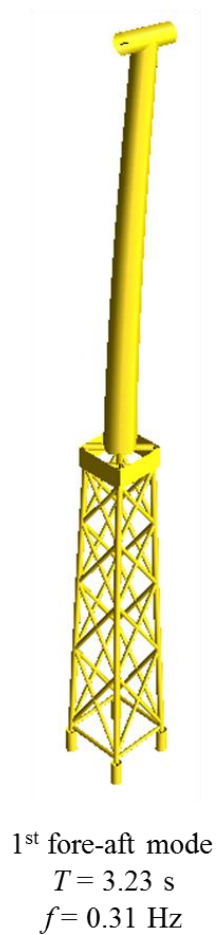

(a)

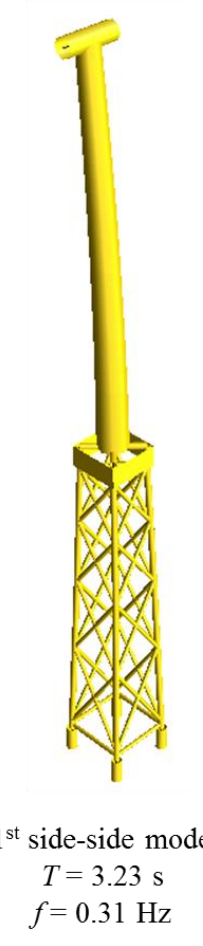

(b)

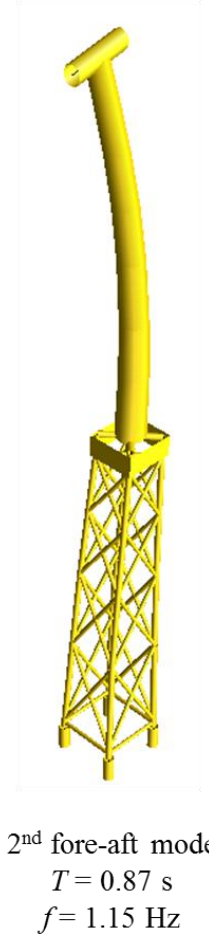

(c)

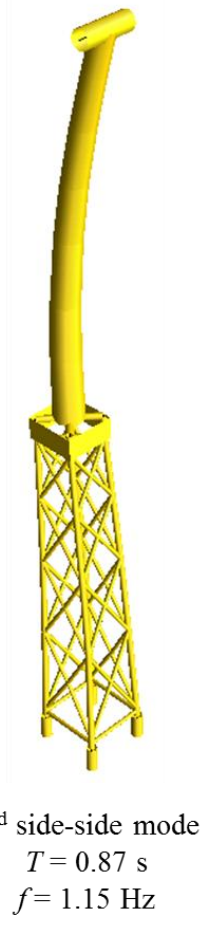

(d)

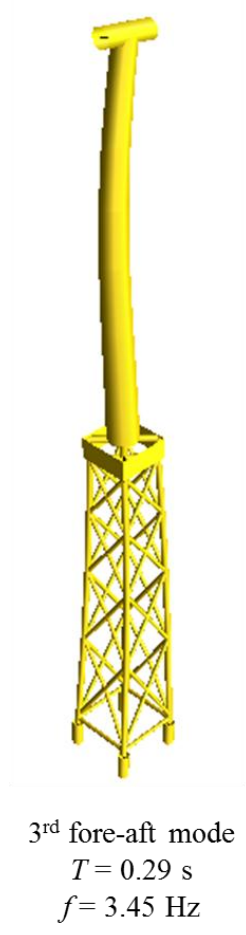

(e)

Figure 4 The first five lateral mode shapes and corresponding periods $(T)$ and frequencies (f) for Model \#1.

\subsection{Wave loading}

The performance of the three structural models considered here is assessed, for dynamic and static analyses and for regular and irregular waves, by incrementally increasing the intensity of wave loading and then tracking the corresponding response of the structure for each increment. The regular waves isolate the effect of wave period by ignoring the short-term uncertainties in an irregular wave profile, thereby providing a clearer comparison with results from static analyses [16]. Additionally, regular waves can be more easily modeled with nonlinear wave kinematics, which are more realistic than linear wave kinematics. In this study, the $10^{\text {th }}$ order stream function theory [27] is selected to model regular waves, because it is best able to model the geometry and kinematics of the large waves that can cause damage to offshore structures, according to recommendations by API [28].

Irregular waves provide a more realistic sequence of wave loading and can therefore provide insight into the dynamic effects associated with unfavorable timing of the wave history sequence. The present study investigates irregular waves using linear wave theory (i.e., Airy theory). The 
procedure for incrementally modeling both regular and irregular waves is summarized as follows:

1) Select a series of extreme wave heights $H_{e, i}$ (for regular) or significant wave heights $H_{\mathrm{s}, \mathrm{i}}$ (for irregular).

2) Calculate the wave period $T_{\mathrm{z}, \mathrm{i}}$ for the extreme wave height $H_{\mathrm{e}, \mathrm{i}}$ of a regular wave according to Eq. 1,

$$
T_{z, i}=11.1 \sqrt{\frac{H_{e, i}}{1.86 g}}
$$

Or calculate the peak spectral period $T_{\mathrm{p}, \mathrm{i}}$ for the significant wave height $H_{\mathrm{s}, \mathrm{i}}$ of an irregular wave spectrum according to Eq. 2, which has been explained in more detail by Valamanesh et al. [29].

$$
T_{p, i}=11.1 \sqrt{\frac{H_{s, i}}{g}}
$$

3) For regular waves, use the wave height $H_{\mathrm{e}, \mathrm{i}}$ and the associated period $T_{\mathrm{z}, \mathrm{i}}$ to generate a regular wave elevation history and calculate the corresponding wave kinematics and wave profile shape using the $10^{\text {th }}$ order nonlinear stream function theory [27]. For irregular waves, use the significant wave height $H_{\mathrm{s}, \mathrm{i}}$ and the associated period $T_{\mathrm{p}, \mathrm{i}}$ to generate a wave spectrum, which is sampled to generate random wave kinematics and wave histories using the inverse Fourier transform and linear wave theory.

4) Perform time-domain dynamic analysis of the structure under each of the wave time histories from Step 3 and record the structural response (e.g., base shear).

5) Perform equivalent static analysis of the structure under the maximum loading that will occur at the given wave intensity. Details on dynamic and equivalent static analysis under regular and irregular wave models used in the example are provided later in Section 3.1 and 3.2.

6) Calculate the ratio of the response calculated in Step 4 to a comparable static response from Step 5 to assess the extent of dynamic amplification.

In Step 4, hydrodynamic loading caused by the waves is calculated using a modified form of the Morison Equation [30], which considers the relative velocity between the structure and fluid [31]. 
All the tubular members of the jacket are modeled with a drag coefficient $C_{\mathrm{D}}=1.2$ and inertia coefficient $C_{\mathrm{M}}=2.0$. Some of the analyses considered here include the situation where the wave surface interacts with the deck of the jacket, creating so-called wave-in-deck forces, which can cause large loads on the structure. Only horizontal wave-in-deck loads are considered here as vertical loads have only a modest effect on structural demands [32]. The wave-in-deck force is calculated using a simplified Morison-type method that is recommended by API [28],

$$
F_{h}=\frac{1}{2} C_{d} A v^{2}
$$

where $\rho$ is the mass density of sea water, $A$ is the "silhouette" deck area, $C_{d}$ is the horizontal force coefficient for the deck, which is equal to 2.5 for the square deck used in this study, and $v$ is the velocity of the wave at the height of the deck. Wave loading is modeled as coming from the upwind direction only and as being perpendicular to the side of the deck of the jacket.

As described in Step 3 above, this paper considers dynamic loading caused by regular and irregular wave time histories, as shown in Figure 5. For the analyses with regular waves, an isolated wave is first generated corresponding to a particular wave theory, which, for all the regular wave analyses in this paper, is the the $10^{\text {th }}$ order stream function wave theory [27]. Eight cycles of the isolated wave are modeled and referred to as the "regular wave time history". As shown in Figure 5(a), the regular wave time history includes an initial ramp, which allows for a gradual initiation of the loading caused by the full wave height $H_{\mathrm{e}, \mathrm{i}}$. As such, the regular wave simulation initiates with "flat sea" conditions with the wave kinematics and elevation scaled linearly to the full wave elevation $H_{\mathrm{e}, \mathrm{i}}$ over a time period $T_{\text {ramp }}$. The phase angle $\theta_{\text {ramp }}$ of the wave is also needed to fully define the initial ramp. The authors conducted a sensitivity study exploring the impact of all combinations of $T_{\text {ramp }}$ between 0 and $5 T_{z, i}$ by a step of $0.5 T_{\mathrm{z}, \mathrm{i}}$ and $\theta_{\text {ramp }}$ between $0^{\circ}$ and $315^{\circ}$ by a step of $45^{\circ}$ and found that the structural response was minimally influenced by these parameters. For this reason, the analyses presented here consider only one set of initial parameters defining the initial ramp: $T_{\text {ramp }}$ equal to $2 T_{\mathrm{z}, \mathrm{i}}$, and $\theta_{\text {ramp }}$ equal to $90^{\circ}$. The maximum dynamic structural response $u_{\text {dynamic }}^{\max }$ from the regular wave analysis is defined as the maximum response (i.e., base shear, in this case) during the time history analysis. 
For the analyses with irregular waves, a one-hour time history is sampled from a JONSWAP spectrum [33] by the inverse Fourier transform. The wave spectrum is defined by $H_{\mathrm{s}, \mathrm{i}}$ and $T_{\mathrm{p}, \mathrm{i}}$. The wave height of isolated irregular waves extracted from the irregular wave history can be considered by multiple measures (see Wei et al. [20] for more details on this issue) and the crest height $H_{\eta}$, is considered here and defined as in Figure 5c. For the irregular wave histories (shown in Figure 5b), the maximum dynamic structural responses relevant to the $j^{\text {th }}$ crest height is $u_{\text {dynamic, }, j}^{\max }$ which is defined as the maximum dynamic response inside the time range of the nearest two zero-crossing points (94 s and $100 \mathrm{~s}$ for the wave shown in Figure 5c). The zero up-crossing period of the $\mathrm{j}^{\text {th }}$ wave $T_{j}$ is also defined in Figure $5 \mathrm{c}$.
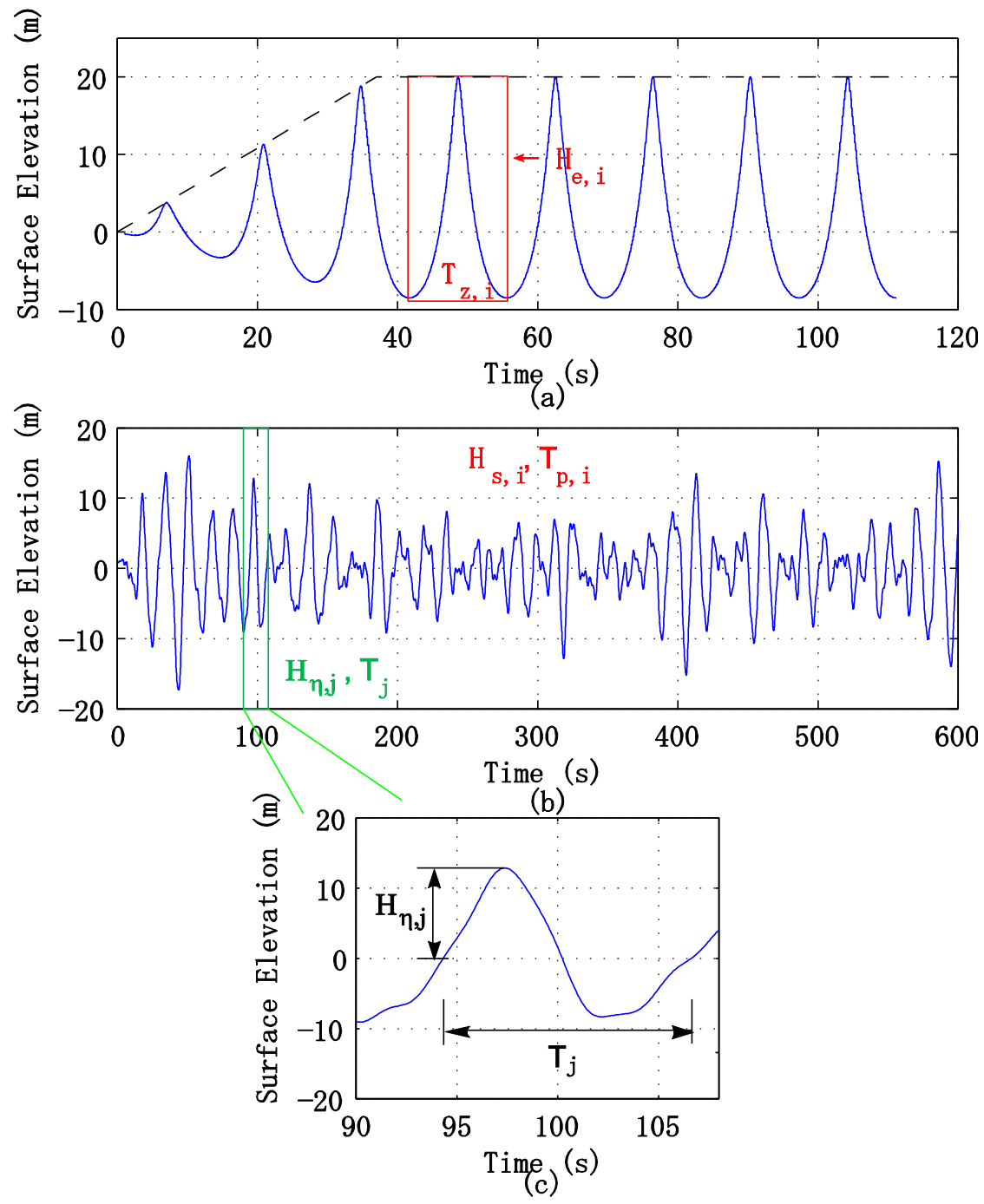

Figure 5 Samples of (a) regular and (b) irregular waves with (c) highlight of the crest height $H_{\eta, j}$ of the $\mathrm{j}^{\text {th }}$ wave in the irregular wave train. 


\subsection{Calculation of dynamic amplification factor}

The difference between the structural response of dynamic and static analyses for the same magnitude of wave loading is quantified with a dynamic amplification factor (DAF),

$$
\mathrm{DAF}=\frac{u_{d y n a m i c}^{\max }}{u_{\text {static }}^{\max }}
$$

where $u_{\text {dynamic }}^{\max }$ is the maximum structural response under dynamic analysis and $u_{\text {static }}^{\max }$ is the maximum response under static analysis. In this study, the considered structural response is the base shear. To calculate the amplification between dynamic and static analyses for regular waves, the equivalent response $u_{\text {static }}^{\max }$ is calculated by static analysis under the wave with wave height $H_{e, i}$ and period $T_{z, i}$, as shown in the red frame in Figure 5a. To calculate the amplification between dynamic and static analyses for irregular waves, the equivalent response $u_{\text {static }}^{\max }$ is calculated by static analysis under the wave with crest height $H_{\eta, j}$ and period $T_{j}$ as shown in the red frame in Figure 5c. Linear Airy wave theory including Wheeler stretching is used to calculate the wave profiles and the corresponding wave kinematics for irregular cases.

The static wave kinematics applied to the structure are those at the instant causing the highest structural response, which, for small diameter drag-dominated components such as the tubes of a jacket structure, generally occurs at the crest of the wave when velocities of the fluid particles are largest [11].

\section{Illustrative Examples and Results}

The scope of the numerical study considered here is organized into two sub-studies, one with regular waves and one with irregular waves. The intent of the study with regular waves is to compare the elastic response of time-domain regular wave analyses and static analyses with the same wave height, while the intent of the study with irregular waves is to examine the effect of wave sequence on the dynamic response. Irregular wave analyses are performed for one-hour irregular sea states with significant wave heights of $H_{\mathrm{s}, \mathrm{i}}=15 \mathrm{~m}, 20 \mathrm{~m}, 25 \mathrm{~m}, 30 \mathrm{~m}$. In this example, the irregular sea state samples with $H_{\mathrm{s}, \mathrm{i}}=15 \mathrm{~m}$ and $20 \mathrm{~m}$ have no waves causing wavein-deck forces, while the irregular wave samples with $H_{\mathrm{s}, \mathrm{i}}=25 \mathrm{~m}$ and $30 \mathrm{~m}$ do have waves causing wave-in-deck forces. For all cases considered here, the water depth is equal to $50 \mathrm{~m}$. 


\subsection{Regular wave analyses}

In this section, the performance of all three models are assessed under regular waves with a large range of extreme wave heights, from $5 \mathrm{~m}$ to $20 \mathrm{~m}$, spaced at $5 \mathrm{~m}$ and from $22 \mathrm{~m}$ to $35 \mathrm{~m}$, spaced at $1 \mathrm{~m}$. The $10^{\text {th }}$ order stream function wave theory [27] is used to calculate the wave kinematics. The DAF is calculated in terms of the maximum base shear from dynamic and static analyses, and the results are provided in terms of base shear versus extreme wave height in Figure 6 and in terms of DAF versus the extreme wave height and the corresponding wave period in Figure 7.

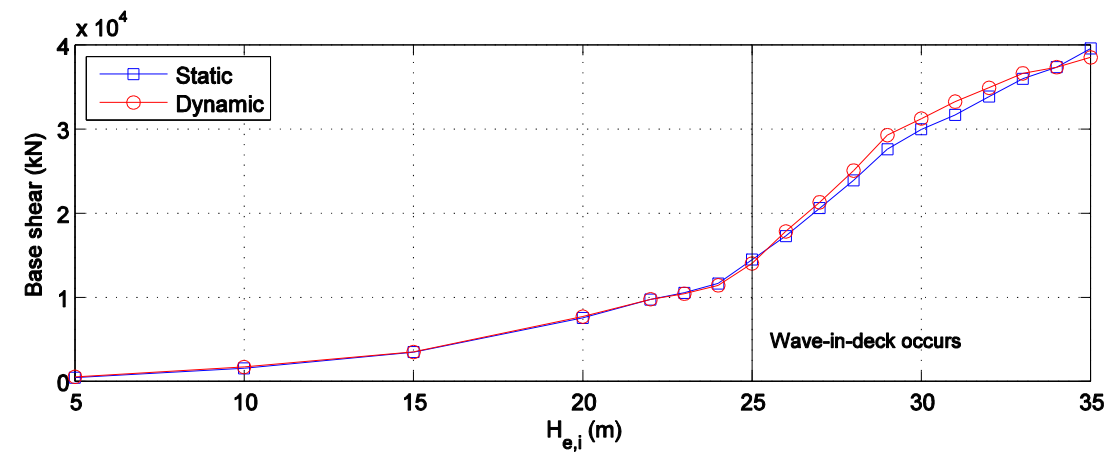

(a)

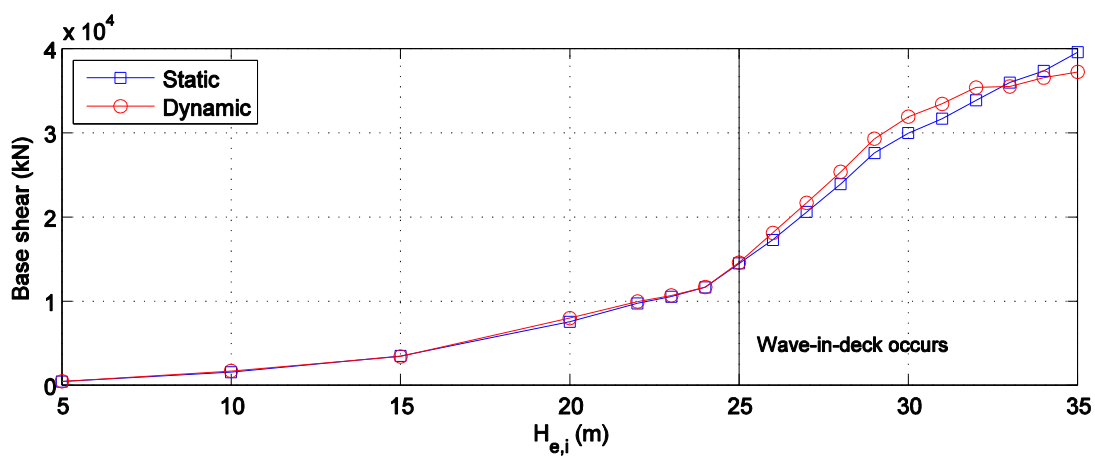

(b)

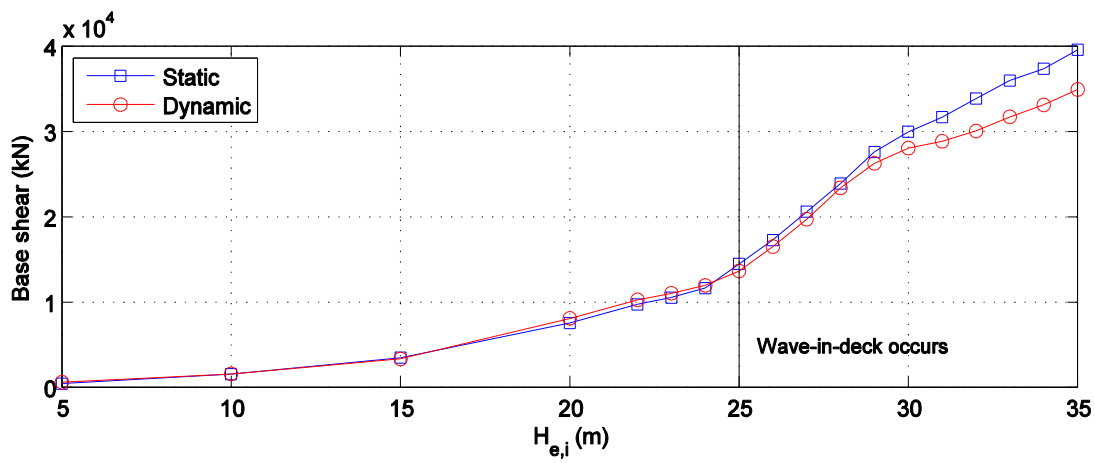

(c)

Figure 6 Comparison between the maximum base shear for static and dynamic analysis for regular waves as a function of extreme wave height $H_{\mathrm{e}, \mathrm{i}}$ for (a) of Model \#1, (b) Model \#2, and (c) Model \#3. 
The extreme wave period $T_{\mathrm{z}, \mathrm{i}}$ is calculated for each extreme wave height $H_{\mathrm{e}, \mathrm{i}}$ according to Eq. 1 . The DAFs of the three models tend to decrease with the increases in $H_{\mathrm{e}, \mathrm{i}}$ and $T_{\mathrm{z}, \mathrm{i}}$, and, for wave heights larger than $10 \mathrm{~m}$, the DAF is always between 0.90 and 1.10 . The periods of the regular waves larger than $10 \mathrm{~m}$ are longer than $10 \mathrm{~s}$ which is significantly longer than the fundamental period of even the most flexible model, Model \#3. As such, the DAFs for these large waves vary little between the models and are close to 1.00 . Waves with heights less than $10 \mathrm{~m}$ have periods closer to the fundamental period of three OWT models and, accordingly, have larger DAFs than those for the larger waves. For waves large enough to cause wave-in-deck forces, the DAFs of three models are never more than 1.10.

In many of the cases considering large waves, the DAF is slightly less than 1.00, implying that a static analysis would overestimate base shear. This result is influenced by the hydrodynamic force model, which considers the relative velocity between the structure and the fluid particles. Time-domain wave analyses using the Morison Equation [30] that use the relative velocity between the structure and the wave particles have been found to overestimate the damping of the offshore structure [31], and such excess damping can act to artificially reduce the dynamic response.

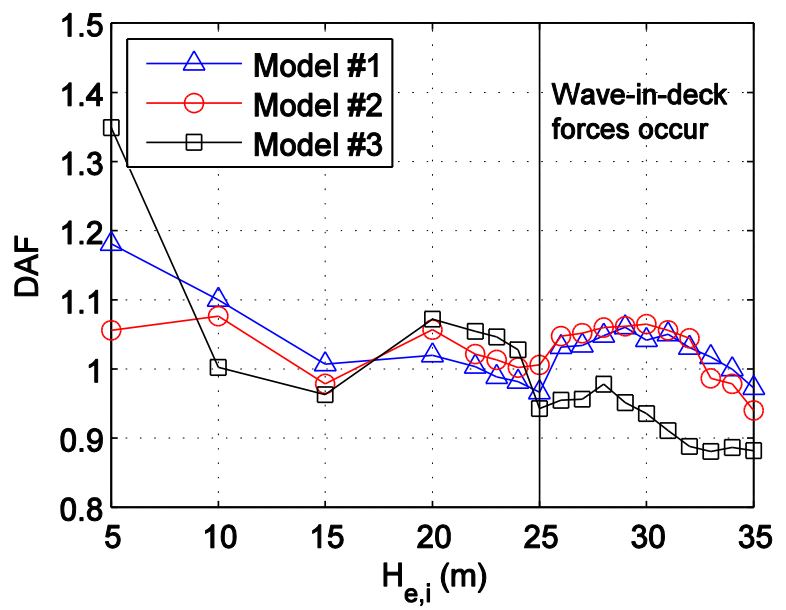

(a)

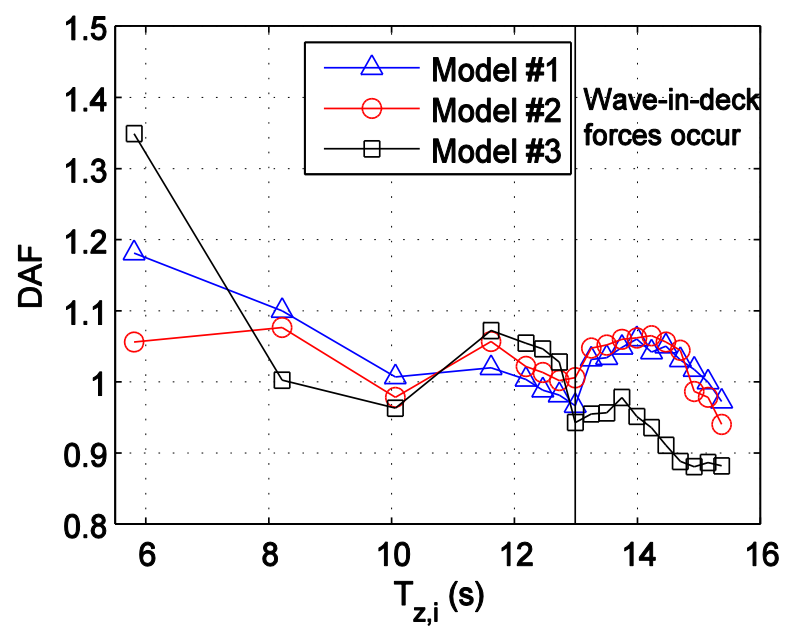

(b)

Figure 7 DAF of the three structural models calculated based on base shear versus (a) extreme wave height $H_{\mathrm{e}, \mathrm{i}}$ and (b) wave period $\boldsymbol{T}_{\mathrm{z}, \mathrm{i} \cdot}$ 


\subsection{Irregular wave analyses}

The focus of these analyses is to study the effect of random, irregular waves on the dynamic response of the three structural models. Figure 8 provides the results for Model \#1 for a one-hour irregular sea state with $H_{\mathrm{s}, \mathrm{i}}=30 \mathrm{~m}$. Figure $8 \mathrm{a}$ shows a scatter plot of the maximum dynamic base shear $u_{\text {dynamic, }, j}^{\max }$ and static base shear $u_{\text {static }, u p, j}^{\max }$ as a function of crest height $H_{\eta}$ and Figure $8 \mathrm{~b}$ gives $\mathrm{DAF}_{\eta}$ as a function of crest height $H_{\eta}$ (blue circles). The trends for $\mathrm{DAF}_{\eta}$ shown in Figure $8 \mathrm{~b}$ are similar to those from the regular wave analyses in Figure 7 a.

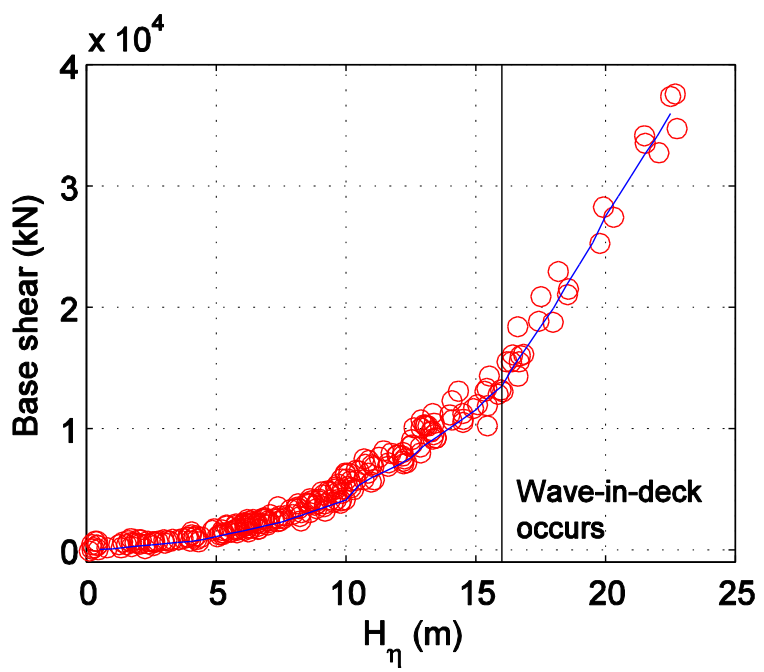

(a)

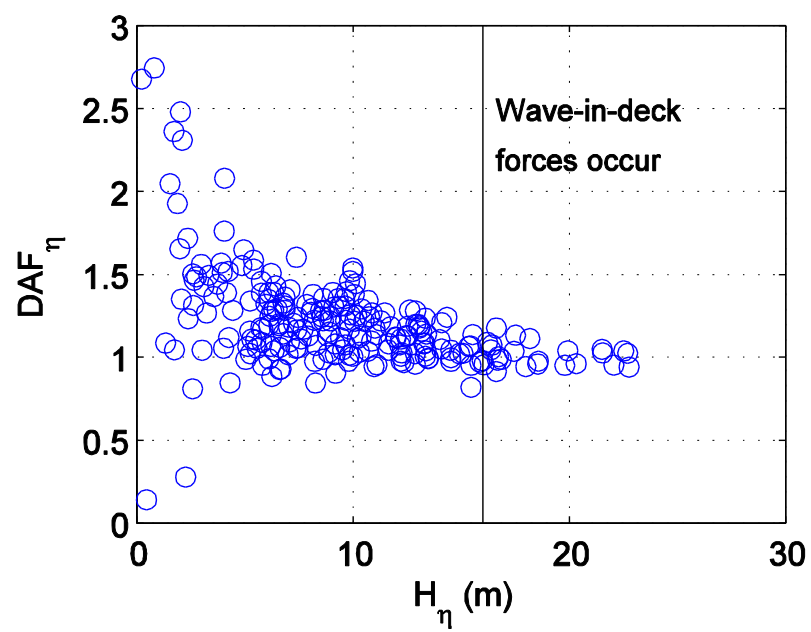

(b)

Figure 8 Base shear and DAF for Model \#1 for a one-hour irregular sea state with $\boldsymbol{H}_{\mathrm{s}, \mathrm{i}}=\mathbf{3 0}$ m for (a) base shear from dynamic analysis (red circles) and static analysis (blue solid line) versus crest height $\eta$, and (b) $\mathrm{DAF}_{\eta}$ versus $\eta$.

Figure 9 shows $\mathrm{DAF}_{\eta}$ from Model \#1 for a one-hour irregular sea state with significant wave heights $H_{\mathrm{s}, \mathrm{i}}(15 \mathrm{~m}, 20 \mathrm{~m}, 25 \mathrm{~m}$ and $30 \mathrm{~m})$ versus crest height $H_{\eta}$. The variability of $\mathrm{DAF}_{\eta}$ is indicated in Figures 9 with red solid lines representing the shape of a normal distribution with identical mean $\mu$ and standard deviation as the DAF for five bins of crest height, $0<H_{\eta} \leq 5,5<H_{\eta}$ $\leq 10,10<H_{\eta} \leq 15,15<H_{\eta} \leq 20$ and $H_{\eta}>20$ (crest heights in meters). Note that some of the subfigures, such as (a), (b) and (c), do not include data in all of the five bins, and, as such, do not include five red lines. The mean $\mu$ and standard deviation $\sigma$ of $\mathrm{DAF}_{\eta}$ for these five ranges of crest height and for each considered structural model and significant wave height are presented in Table 2, along with the number of waves within each range of crest height. For all sea states and 
structural models, the mean $\mu$ and standard deviation $\sigma$ of $\mathrm{DAF}_{\eta}$ decrease as the crest height increases, and, for large waves with crest heights larger than $16 \mathrm{~m}$, which are tall enough to cause wave-in-deck forces, all the DAFs are between 0.90 and 1.10. For waves with crest heights $H_{\eta}$ larger than $10 \mathrm{~m}$, the minimum and maximum of the mean DAF are equal to 0.91 and 1.13 and the minimum and maximum of the extreme DAF (i.e., $\mu \pm 2 \sigma$ ) are equal to 0.78 and 1.40 for all models and significant wave heights. These results, in terms of the mean DAF, are similar to those for the regular wave analyses, however the extreme values of the DAF show how the extremes can differ significantly. It is noted that the mean DAF increases slightly with $H_{\mathrm{s}, \mathrm{i}}$ when comparing identical ranges of $H_{\eta, j}$ for every model. For waves with crest heights $H_{\eta, j}$ larger than $10 \mathrm{~m}$, the mean DAF differs by only a few percent among the three models, reflecting the fact that most of the frequency content of the large irregular waves is lower than the lowest fundamental frequency of the three models considered here.

Table 2 Mean $\mu$ and standard deviation $\sigma$ of the distribution of DAF $_{\eta}$ for a one-hour irregular sea state and different $\mathrm{H}_{\mathrm{s}, \mathrm{i}}$, structural model, and ranges of $\mathrm{H}_{\eta}$.

\begin{tabular}{|c|c|c|c|c|c|c|c|c|c|c|c|c|c|c|}
\hline \multirow{3}{*}{ Crest height (m) } & \multicolumn{7}{|c|}{$H_{\mathrm{s}, \mathrm{i}}=15 \mathrm{~m}$} & \multicolumn{7}{|c|}{$H_{\mathrm{s}, \mathrm{i}}=20 \mathrm{~m}$} \\
\hline & \multirow{2}{*}{$\begin{array}{c}\text { \# of } \\
\text { waves }\end{array}$} & \multicolumn{2}{|c|}{ Model \#1 } & \multicolumn{2}{|c|}{ Model \#2 } & \multicolumn{2}{|c|}{ Model \#3 } & \multirow{2}{*}{$\begin{array}{c}\text { \# of } \\
\text { waves }\end{array}$} & \multicolumn{2}{|c|}{ Model \#1 } & \multicolumn{2}{|c|}{ Model \#2 } & \multicolumn{2}{|c|}{ Model \#3 } \\
\hline & & $\mu$ & $\sigma$ & $\mu$ & $\sigma$ & $\mu$ & $\sigma$ & & $\mu$ & $\sigma$ & $\mu$ & $\sigma$ & $\mu$ & $\sigma$ \\
\hline $0<H_{\eta, j} \leq 5$ & 192 & 1.64 & 1.54 & 1.59 & 1.35 & 1.72 & 1.64 & 127 & 2.17 & 2.78 & 2.03 & 2.56 & 2.87 & 4.00 \\
\hline $5<H_{\eta, j} \leq 10$ & 122 & 1.06 & 0.12 & 1.06 & 0.14 & 1.06 & 0.15 & 119 & 1.11 & 0.13 & 1.11 & 0.15 & 1.15 & 0.16 \\
\hline $10<H_{\eta, j} \leq 15$ & 9 & 0.96 & 0.04 & 0.98 & 0.04 & 0.93 & 0.05 & 34 & 1.03 & 0.09 & 1.02 & 0.09 & 1.00 & 0.10 \\
\hline$H_{\eta, \mathrm{j}}>15$ & \multicolumn{7}{|c|}{ N/A } & 5 & 0.92 & 0.05 & 0.94 & 0.05 & 0.91 & 0.05 \\
\hline \multirow{3}{*}{ Crest height (m) } & \multicolumn{7}{|c|}{$H_{\mathrm{s}, \mathrm{i}}=25 \mathrm{~m}$} & \multicolumn{7}{|c|}{$H_{\mathrm{s}, \mathrm{i}}=30 \mathrm{~m}$} \\
\hline & \multirow{2}{*}{$\begin{array}{c}\# \text { of } \\
\text { waves }\end{array}$} & \multicolumn{2}{|c|}{ Model \#1 } & \multicolumn{2}{|c|}{ Model \#2 } & \multicolumn{2}{|c|}{ Model \#3 } & \# of & \multicolumn{2}{|c|}{ Model \#1 } & \multicolumn{2}{|c|}{ Model \#2 } & \multicolumn{2}{|c|}{ Model \#3 } \\
\hline & & $\mu$ & $\sigma$ & $\mu$ & $\sigma$ & $\mu$ & $\sigma$ & waves & $\mu$ & $\sigma$ & $\mu$ & $\sigma$ & $\mu$ & $\sigma$ \\
\hline $0<H_{\eta, j} \leq 5$ & 87 & 2.61 & 3.58 & 2.18 & 3.27 & 3.45 & 4.87 & 50 & 2.77 & 3.90 & 2.02 & 3.43 & 3.85 & 5.52 \\
\hline $5<H_{\eta, j} \leq 10$ & 105 & 1.14 & 0.16 & 1.12 & 0.16 & 1.19 & 0.18 & 95 & 1.20 & 0.17 & 1.17 & 0.18 & 1.29 & 0.22 \\
\hline $10<H_{\eta, j} \leq 15$ & 58 & 1.10 & 0.15 & 1.09 & 0.14 & 1.08 & 0.15 & 59 & 1.13 & 0.12 & 1.11 & 0.11 & 1.12 & 0.13 \\
\hline $15<H_{\eta, j} \leq 20$ & 13 & 1.01 & 0.10 & 1.01 & 0.10 & 1.01 & 0.10 & 25 & 1.02 & 0.08 & 1.01 & 0.08 & 1.02 & 0.08 \\
\hline$H_{\eta, \mathrm{j}}>20$ & 1 & 0.98 & 0.00 & 0.97 & 0.00 & 0.94 & 0.00 & 7 & 1.00 & 0.05 & 1.00 & 0.04 & 0.98 & 0.05 \\
\hline
\end{tabular}




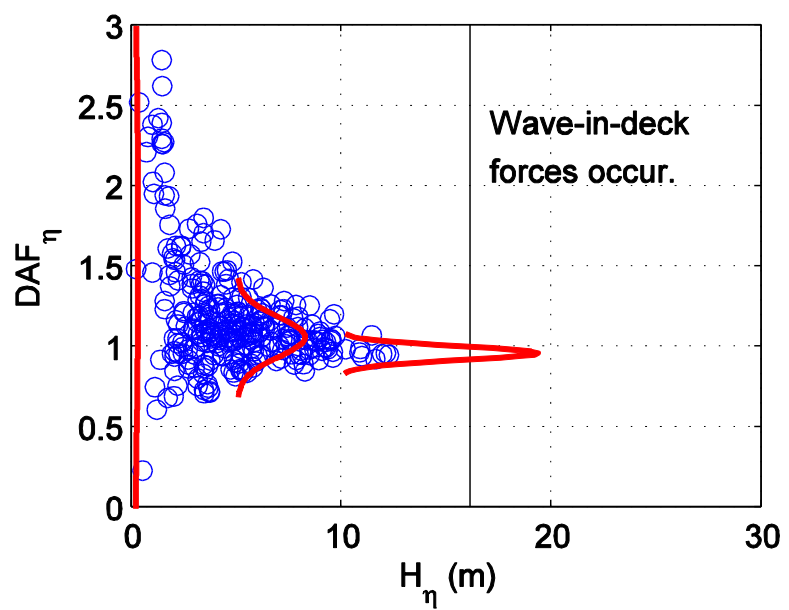

(a)

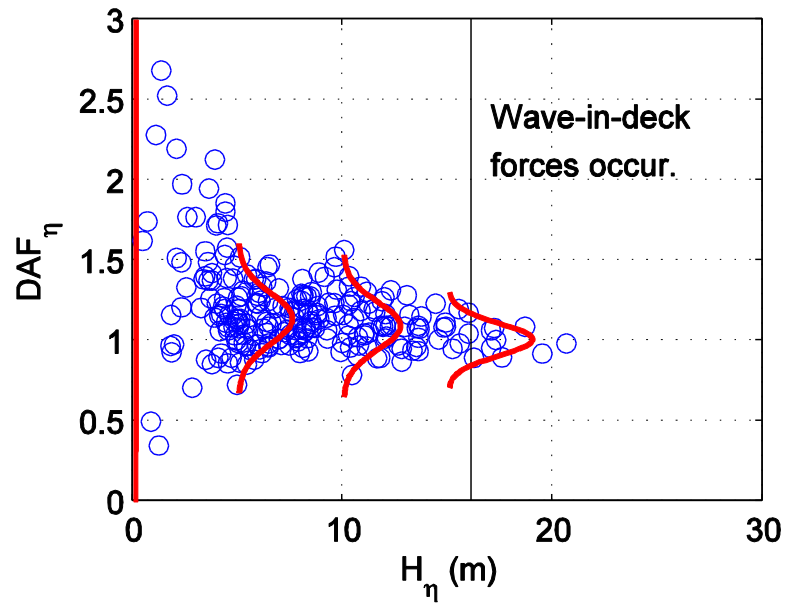

(c)

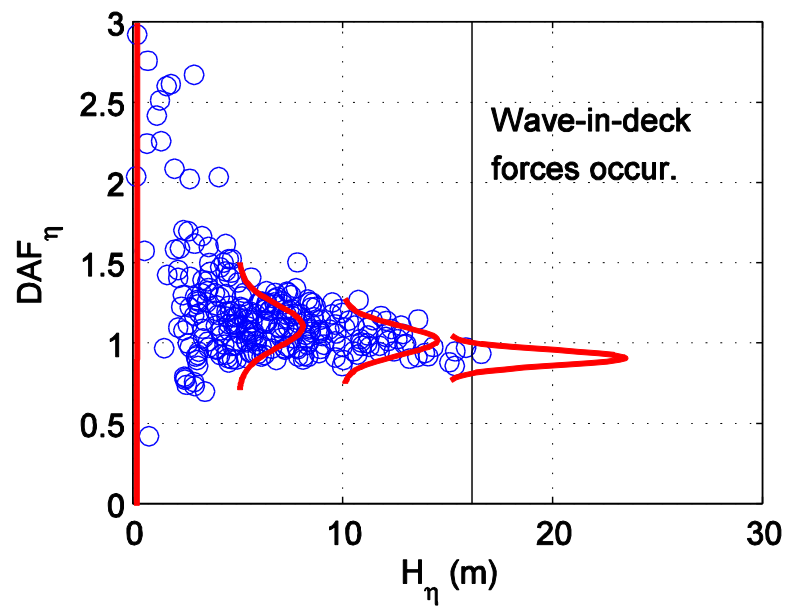

(b)

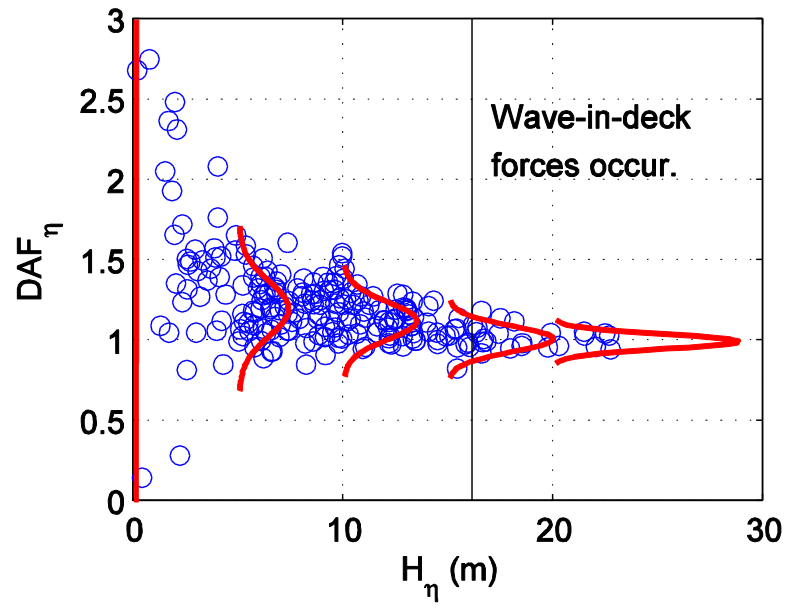

(d)

Figure $9 \mathrm{DAF}_{\boldsymbol{\eta}}$ of Model \#1 for a one-hour irregular sea state versus crest height $\mathbf{H}_{\boldsymbol{\eta}}$ for $\boldsymbol{H}_{\mathrm{s}, \mathrm{i}}$ equal to (a) $15 \mathrm{~m}$, (b) $20 \mathrm{~m}$, (c) $25 \mathrm{~m}$, and (d) $30 \mathrm{~m}$. Red solid lines indicate the distribution of DAF $\eta$ between $[\mu-2 \sigma, \mu+2 \sigma]$.

\section{Conclusions}

This paper has presented results from a series of analyses designed to quantify the extent of dynamic amplification of the elastic response of OWTs supported by jackets under wave loading. The analyses are conducted in the time-domain and consider the effects of regular and irregular wave time histories on three structural models with a range of fundamental periods (between 2.5 $\mathrm{s}$ and $4.9 \mathrm{~s}$ ). All of the structural models are linear with elastic materials. The results illustrate that the dynamic amplification factor (DAF; i.e., the ratio between the maximum base shear predicted by a dynamic analysis and an equivalent static analysis) decreases with increasing 
wave height. For wave heights larger than $10 \mathrm{~m}$, the DAF in terms of base shear is always between 0.90 and 1.10 for the regular wave analyses. For the irregular wave analyses, the mean DAFs for crest heights larger than $10 \mathrm{~m}$ are always between 0.91 and 1.13 , while the extreme values $(\mu \pm 2 \sigma)$ of the DAF are always between 0.78 and 1.40 . For waves larger than $10 \mathrm{~m}$, the effect of the fundamental period of the structure on the DAF is shown to be small for the conditions considered here because large waves have periods significantly longer than the fundamental periods of all the models considered here. Statistics of the distributions of DAF for the irregular wave analyses are calculated for each structural model and for bins of wave crest heights. These statistics show that the mean $\mu$ and standard deviation $\sigma$ of the DAF tend to decrease as the crest height increases for all conditions considered here. For the irregular wave models considered here, the DAFs for waves with large crest heights (i.e., greater than $10 \mathrm{~m}$ ) are close to 1.00 in the mean sense, however extreme values of the DAF from irregular waves can be significantly larger or smaller than 1.00 .

This paper focuses on the development of an approach to assess the extent of dynamic effects in the response of OWT jackets subjected to wave loads. The numerical results provided herein are based on only three structural models of OWT jackets and include several modeling assumptions. Additional numerical and experimental studies are needed to generalize the results.

\section{Acknowledgement}

This material is based upon work supported by the National Science Foundation under Grant Nos. CMMI-1234560 and CMMI-1234656, the Massachusetts Clean Energy Center, the University of Massachusetts at Amherst, and Northeastern University. Any opinions, findings, and conclusions expressed in this material are those of the authors and do not necessarily reflect the views of the National Science Foundation or other sponsors. The authors would like to thank Dr. Tore Holmas of USFOS Company for his assistance with this research. 


\section{Reference}

[1] Krawinkler H, Zareian F, Medina RA, Ibarra LF. Decision support for conceptual performance-based design. Earthquake Engineering \& Structural Dynamics. 2006;35:115-33.

[2] Vision SEAOC. Performance based seismic engineering of buildings. Sacramento, Calif: Structural Engineers Association of California; 1995.

[3] Hose YD, Seible F. Performance evaluation database for concrete bridge components and systems under simulated seismic loads: Pacific Earthquake Engineering Research Center; 1999.

[4] Nuta E, Christopoulos C, Packer JA. Methodology for seismic risk assessment for tubular steel wind turbine towers: application to Canadian seismic environment. Canadian Journal of Civil Engineering. 2011;38:293-304.

[5] Fallon MB. A Probabilistic Deformation Demand Model and Fragility Estimates for Asymmetric Offshore Jacket Platforms 2012.

[6] Spence S, Chuang W, Tabbuso P, Bernardini E, Kareem A, Palizzolo L et al. PerformanceBased Engineering of Wind-Excited Structures: A General Methodology. Geotechnical and Structural Engineering Congress 2016: American Society of Civil Engineers; 2016. p. 1269-82.

[7] Taflanidis AA, Loukogeorgaki E, Angelides DC. Offshore wind turbine risk quantification/evaluation under extreme environmental conditions. Reliab Eng Syst Safe. 2013;115:19-32.

[8] Kim S, D'Amore E. Push - over Analysis Procedure in Earthquake Engineering. Earthquake Spectra. 1999;15:417-34.

[9] Barros RC, Almeida R. Pushover analysis of asymmetric three - dimensional building frames. Journal of Civil Engineering and Management. 2005;11:3-12.

[10] Stewart G, Moan T, Amdahl J, Eide OI. Nonlinear re-assessment of jacket structures under extreme storm cyclic loading: Part I-philosophy and acceptance criteria. 12th International Conference on Offshore Mechanics and Arctic Engineering: ASME; 1993. p. 491-502.

[11] Wei K, Arwade SR, Myers AT. Incremental wind-wave analysis of the structural capacity of offshore wind turbine support structures under extreme loading. Eng Struct. 2014;79:58-69.

[12] Ghobarah A. Performance-based design in earthquake engineering: state of development. Eng Struct. 2001;23:878-84.

[13] Vamvatsikos D, Cornell CA. Incremental dynamic analysis. Earthquake Engineering \& Structural Dynamics. 2002;31:491-514.

[14] Tabbuso P, Spence SMJ, Palizzolo L, Pirrotta A, Kareem A. An efficient framework for the elasto-plastic reliability assessment of uncertain wind excited systems. Structural Safety. 2016;58:69-78.

[15] Judd JP, Charney FA. Inelastic Behavior and Collapse Risk for Buildings Subjected to Wind Loads. Structures Congress 2015. Portland, Oregon2015. p. 2483-96.

[16] Golafshani AA, Bagheri V, Ebrahimian H, Holmas T. Incremental wave analysis and its application to performance-based assessment of jacket platforms. J Constr Steel Res. 2011;67:1649-57.

[17] Jensen JJ. Dynamic amplification of jack-up platforms subjected to non-Gaussian wave loads. Journal of Research of the National Institute of Standards and Technology. 1993;99:45564. 
[18] Horn J-TH, Amdahl J, Haver SK. Dynamic amplification of drag dominated structures in irregular seas. OCEANS'15 MTS/IEEE. Washington: IEEE; 2015.

[19] Kim DH, Lee SG, Lee IK. Seismic fragility analysis of 5 MW offshore wind turbine. Renew Energ. 2014;65:250-6.

[20] Wei K, Arwade SR, Myers AT, Hallowell S, Hajjar JF, Hines EM et al. Toward performance-based evaluation for offshore wind turbine jacket support structures. Renew Energ. 2016;97:709-21.

[21] Vemula NK, DeVries W, Fischer T, Cordle A, Schmidt B. Design solution for the upwind reference offshore support structure. Upwind deliverable D425: Rambøll; 2010.

[22] Jonkman JM, Butterfield S, Musial W, Scott G. Definition of a 5-MW reference wind turbine for offshore system development. National Renewable Energy Laboratory Colorado; 2009.

[23] Holmas T, Amdahl J, Emami Azadi MR. USFOS, a computer program for ultimate strength analysis of framed structures (with Pile-Soil Module). Norway; 2006.

[24] Hensel J, Sharma MSR, Baxter CDP, Hu SLJ. Development of a technology type factor for jacket structures for offshore wind turbines in Rhode Island. J Renew Sustain Energy. 2012;4.

[25] Shirzadeh R, Weijtjens W, Guillaume P, Devriendt C. The dynamics of an offshore wind turbine in parked conditions: a comparison between simulations and measurements. Wind Energy. 2015;18:1685-702.

[26] Correia HJD, Mendes AnC, Oliveira CAFS. Structural Analysis of an Offshore Jacket Model Under Seismic Excitation. ASME 2008 27th International Conference on Offshore Mechanics and Arctic Engineering. Estoril, Portugal. 2008. p. 265-74.

[27] Fenton J. Nonlinear wave theories. The Sea. 1990;9:3-25.

[28] API R. Recommended Practice for Planning, Designing, and Constructing Fixed Offshore Platforms-Working Stress Design. API RP 2A-WSD 21st Edition. Washington, D.C.: API Publishing Services; 2005.

[29] Valamanesh V, Myers AT, Arwade SR. Multivariate analysis of extreme metocean conditions for offshore wind turbines. Structural Safety. 2015;55:60-9.

[30] Morison JR, O'Brien MP, Johnson JW, Schaaf SA. The Force Exerted by Surface Waves on Piles. Journal of Petroleum Technology. 1950;2:149-54.

[31] Laya EJ, Connor JJ, Sunder SS. Hydrodynamic forces on flexible offshore structures. Journal of engineering mechanics. 1984;110:433-48.

[32] Loch K. The Effects of Wave Induced Vertical Deck Loads on Ultimate Limit State Static Pushover Analyses Results. Marine Technology \& Management Group, Department of Civil \& Environmental Engineering, University of California at Berkeley, Berkeley, CA. 1994.

[33] Hasselmann K, Barnett T, Bouws E, Carlson H, Cartwright D, Enke K et al. Measurements of wind-wave growth and swell decay during the Joint North Sea Wave Project (JONSWAP). 1973. 